\title{
TERRESTRIAL ECOMORPHS FROM THE UPPER TRIASSIC AND UPPER CRETACEOUS
} OF NORTH AMERICA

MURRY, Phillip A., Dept. of Physical Sciences, Tarleton State University, Stephenville, TX 76402, U.S.A; LONG, Robert A., P.O. Box 5186, Pleasanton, CA 94566, U.S.A.; RUSSELL*, D. A., North Carolina State University/North Carolina State Museum of Natural Sciences, Raleigh, NC 27695-8208, U.S.A.

Terrestrial reptiles from the Upper Triassic of the southwestern United States and the Upper Cretaceous of the northern interior of the United States and adjacent Canada exhibit numerous ecomorphic parallels. "Mesozoic-style" adaptations, such as edentulous beaks, neck frills, elongated necks, pectoral spikes and armor plates, were widespread by late Triassic time.

In size and gross body form, nearly three dozen genera of Upper Triassic reptiles converged on Upper Cretaceous teiid and varanoid lizards, including procolophonids, sphenodontids, prolacertids and trilophosaurs (cf. Polyglyphanodon). Within aquatic communities, doswellids resembled Cretaceous champsosaurs, although their necks were longer and their bodies more heavily armored. Some phytosaurs resembled Cretaceous gavialomorphs, others resembled crocodiles, and yet others resembled the giant Deinosuchus in their narrow, deep rostra. Perhaps metoposaurs were ecomorphically comparable to broad-snouted Cretaceous alligators. No Triassic turtles have been found in the southwest, although they are very abundant in the Cretaceous of the northern interior.

Among terrestrial herbivores, rhynchosaurs resembled Cretaceous protoceratopsids in their broad skulls, hooked premaxillae and dentaries, and dentitions confined to the posterior part of the jaws. Large dicynodonts bore beaked skulls with enlarged squamosals, and a body form reminiscent of that of Cretaceous ceratopsids. However, neither form was as abundant as its Cretaceous counterpart. The Triassic aetosaurs and Cretaceous ankylosaurs possessed well-developed body armor. Some aetosaurs bore enormous pectoral horns similar to those in Cretaceous nodosaurs. However, the flattened, discoidal carapaces of other aetosaurs were not duplicated by the less diverse and less flexible carapaces of ankylosaurs. Skeletal fragments indicate the presence of bulky prosauropods 4 to 6 meters long, which remotely resembled Cretaceous hadrosaurs. Isolated teeth in the southwestern Triassic suggest the presence of ornithischians 0.5 to 4 meters long.

Among terrestrial carnivores, Triassic rauisuchians exhibit a range of morphotypes broadly similar to those of theropods. Although their skulls often exhibit striking similarities to those of tyrannosaurids, none were obligatory bipeds. One small rauisuchian (Chatterieea, possibly associated with an edentulous skull) strikingly resembled ornithomimids. The Triassic theropod Chindesaurus resembled troodontids in its short body and long hind legs, but the body of "Coelophysis" differed from that of Cretaceous theropods in its long torso and short hind limbs. Most Triassic theropods were lightly built creatures less than 3 meters long, although an incomplete skeleton indicates one robust form at least 5 meters long.

Major differences between Upper Triassic and Upper Cretaceous assemblages include the lesser abundance of armored forms in Upper Cretaceous assemblages and the greater abundance of larger, often bipedal reptiles. Anatomical specializations such as dental batteries, differentiated vertebral columns, narrow bodies, gracile limbs and fewer digits are more widely distributed among Upper Cretaceous forms. Some of these differences may be attributable to increasing fitness. Although imperfect, ecomorphic continuity nevertheless exceeded phylogenetic continuity through the approximately 150 million years separating late Triassic from late Cretaceous time. 